\title{
Fratricide in Streptococcus pneumoniae: contributions and role of the cell wall hydrolases CbpD, LytA and LytC
}

\author{
Vegard Eldholm, Ola Johnsborg, Kristine Haugen, Hilde Solheim Ohnstad \\ and Leiv Sigve Håvarstein
}

Correspondence

Leiv Sigve Håvarstein

sigve.havarstein@umb.no

Received 1 December 2008

Revised 4 March 2009

Accepted 31 March 2009
Department of Chemistry, Biotechnology and Food Science, Norwegian University of Life Sciences, N-1432 Ås, Norway

\begin{abstract}
Pneumococci that have developed the competent state kill and lyse non-competent sister cells and members of closely related species during co-cultivation in vitro. The key component in this process, called fratricide, is the product of the late competence gene $c b p D$. In addition, the peptidoglycan hydrolases LytA and LytC are required for efficient lysis of target cells. Here, we have investigated the relative contribution and possible role of each of the proteins mentioned above. Previous studies have shown that CbpD is produced exclusively by competent cells, whereas LytA and LytC can be provided by the competent attackers as well as the non-competent target cells. By using an improved assay to compare the effect of cis- versus trans-acting LytA and LytC, we were able to show that target cells are lysed much more efficiently when LytA and LytC are provided in cis, i.e. by the target cells themselves. Western analysis demonstrated that considerable amounts of LytC are present in the growth medium. In contrast, we were not able to detect any extracellular LytA. This finding indicates that LytA- and LytC-mediated fratricide represent different processes. In the absence of LytA and LytC, only a tiny fraction of the target cells were lysed, demonstrating that $\mathrm{CbpD}$ does not function efficiently on its own. However, in the presence of $1 \mathrm{mM}$ EDTA, the fraction of target cells lysed directly by CbpD increased dramatically, indicating that divalent cations are involved in the regulation of fratricide under natural conditions.
\end{abstract}

\section{INTRODUCTION}

Streptococcus pneumoniae is an important human pathogen with remarkable adaptation capabilities. It is the most common single cause of community-acquired infections, including bacterial pneumonia, bacteraemia, meningitis and otitis media. The pneumococcus causes 1-2 million deaths per year, most of which occur in developing countries, where this bacterial species is probably the most important pathogen of early infancy (Obaro \& Adegbola, 2002).

Bacteria that have the ability to take up naked DNA from the environment and incorporate this DNA into their genomes by homologous recombination are said to be competent for natural genetic transformation. So far, about 70 different species of bacteria, many of which are important pathogens, have been shown to possess this

Abbreviations: CSP, competence-stimulating peptide; LTA, lipoteichoic acid; TA, teichoic acid.

Details of the construction of $S$. pneumoniae mutants, and a table of primers, are available as supplementary material with the online version of this paper. property (Johnsborg et al., 2007). In S. pneumoniae and related commensal streptococci, natural genetic transformation mediates intraspecies as well as interspecies gene transfer. It has for instance been firmly established that gene exchange by this mechanism has contributed significantly to the increasing incidence of penicillinresistant S. pneumoniae worldwide (Hakenbeck, 1995; Chi et al., 2007), a development that constitutes a major threat to public health (Jenkins et al., 2008). Gene exchange by natural transformation gives the pneumococcus access to a large gene pool, which it shares with other pneumococcal strains and closely related commensal streptococci (Hiller et al., 2007). Consequently, genes present in the common gene pool that give a selective advantage under certain types of stress (e.g. vaccination or treatment with antibiotics) will spread rapidly among these bacteria.

Recently, we reported that a competence-controlled predatory mechanism dramatically increases the efficiency of lateral gene transfer in S. pneumoniae and related commensal species (Johnsborg et al., 2008). When developing the competent state, streptococci such as $S$. pneumoniae, Streptococcus mitis and Streptococcus oralis 
express a putative murein hydrolase, $\mathrm{CbpD}$, which mediates lysis of non-competent target cells present in the same environment. As the DNA released from the lysed cells can be taken up by the competent attacker cells, the rate of gene transfer is greatly increased. Induction of the competent state in $S$. pneumoniae is controlled by the ComABCDE quorum-sensing system (Håvarstein et al., 1995; Pestova et al., 1996). Although the closely related ComABCDE systems of $S$. mitis and $S$. oralis have not been studied in the same detail as their pneumococcal counterpart, there is little doubt that these proteins have the same function in all three species. The ComABCDE quorum-sensing system consists of the comC-encoded competence-stimulating peptide (CSP) (Håvarstein et al., 1995), its secretion apparatus (ComAB) (Hui \& Morrison, 1991), and a two-component signal transduction pathway (ComDE) that senses the concentration of extracellular CSP (Håvarstein et al., 1996). When the CSP pheromone reaches a critical concentration, transcription of the early and late competence genes is initiated, and the cells enter the competent state. The response regulator ComE, which upon phosphorylation binds to a conserved direct-repeat motif in the promoter region of target genes (Ween et al., 1999), directly controls the expression of about 20 early competence genes. Among these are the gene(s) encoding ComX, an alternative sigma factor required for expression of approximately 80 late competence genes (Lee \& Morrison, 1999). Curiously, only a fraction of the CSP-responsive genes, 7 early and 14 late gene products, are required for the transformation process (Dagkessamanskaia et al., 2004; Peterson et al., 2004). In addition, a few CSP-responsive genes are involved in the predatory lysis mechanism described above (for a review, see Claverys \& Håarstein, 2007). These include the early competence gene comM (Håvarstein et al., 2006), and the two late competence genes $c b p D$ and $l y t A$ (Steinmoen et al., 2003; Guiral et al., 2005; Kausmally et al., 2005). The com $M$ gene encodes an immunity protein that protects the competent cells against their own lysins (Håvarstein et al., 2006). The mechanism behind this protection is not known. Similarly, the exact mode of action of the key component of the lysis mechanism, CbpD, has not been determined yet. However, since its CHAP (cysteine, histidine-dependent amidohydrolase/peptidase) domain is homologous to the corresponding domain of a number of cell wall hydrolases that cleave peptide bonds within the stem peptides of bacterial peptidoglycan, it is reasonable to assume that CbpD performs the same function (Bateman \& Rawlings, 2003; Rigden et al., 2003). The major pneumococcal autolysin LytA is expressed in non-competent cells, but its expression increases during competence (Mortier-Barrière et al., 1998; Dagkessamanskaia et al., 2004; Peterson et al., 2004). An additional constitutively expressed cell wall hydrolase, LytC, which is not part of the competence regulon, has also been shown to contribute to the lysis mechanism (Guiral et al., 2005).

These proteins, CbpD, LytA and LytC, appear to be the principal players mediating lysis of non-competent target cells during fratricide in liquid cultures. However, when attacker and target cells are grown together within blood agar plates, two additional components, the bacteriocins CibAB, are involved as well (Guiral et al., 2005). For reasons unknown, these bacteriocins do not contribute to lysis of target cells in liquid cultures (Håvarstein et al., 2006, unpublished results).

In the current study, we have investigated the role and relative contributions of $\mathrm{CbpD}$, LytA and LytC to fratricide in planktonic cultures of $S$. pneumoniae. Our results show that $\mathrm{CbpD}$ alone can kill and lyse target cells. However, the effect of $\mathrm{CbpD}$ is strongly amplified by the action of LytC and LytA, whose activities are directly or indirectly triggered by CbpD. Remarkably, in the presence of $1 \mathrm{mM}$ EDTA, the dependency of CbpD on LytA and LytC decreases considerably, and CbpD becomes able to kill and lyse target cells efficiently on its own.

\section{METHODS}

Bacterial strains and growth conditions. Pneumococcal strains and plasmids used in this study are described in Table 1. The bacteria were grown in C medium (Lacks \& Hotchkiss, 1960). Samples analysed on Western blots were collected from cultures grown in C medium without added BSA.

Construction of $\boldsymbol{S}$. pneumoniae mutants. Construction of the DNA fragments and plasmids used in mutagenesis of the various streptococcal strains is described in the supplementary online material. The sequences of all primers used are given in Supplementary Table S1. DNA was introduced into S. pneumoniae by natural transformation. Pneumococcal cultures grown at $37{ }^{\circ} \mathrm{C}$ to an $\mathrm{OD}_{550}$ of around 0.1 were induced to competence using 100 $250 \mathrm{ng} \mathrm{ml}^{-1}$ of CSP (N-EMRLSKFFRDFILQRKK-C). After phenotypic expression in liquid medium for $90-120 \mathrm{~min}$ at $37^{\circ} \mathrm{C}, \mathrm{S}$. pneumoniae transformants were selected by plating on Todd-Hewitt agar supplemented with chloramphenicol $\left(4.5 \mu \mathrm{g} \mathrm{ml}{ }^{-1}\right)$, kanamycin $\left(400 \mu \mathrm{g} \mathrm{ml}^{-1}\right)$, streptomycin $\left(200 \mu \mathrm{g} \mathrm{ml}^{-1}\right)$, spectinomycin $(200 \mu \mathrm{g}$ $\left.\mathrm{ml}^{-1}\right)$ or tetracycline $\left(0.2 \mu \mathrm{g} \mathrm{ml} \mathrm{m}^{-1}\right)$.

Quantification of $\boldsymbol{\beta}$-galactosidase release from target cells. To determine the relative contributions of $c b p D$, lytA and $l y t C$ to competence-induced lysis, the amount of $\beta$-galactosidase released from lysed target cells during co-cultivation with competent attackers was measured. All target cells contained a lacZ gene from Escherichia coli fused to a highly expessed gene termed hirL (SPD_1984). In addition, the endogenous $\beta$-galactosidase gene ( $e b g)$ was disrupted in both target and attacker cells. The procedure used was essentially as described by Steinmoen et al. (2002). Briefly, cultures of competenceinducible and non-inducible target cells were grown in parallel at $37{ }^{\circ} \mathrm{C}$ in a water bath. At $\mathrm{OD}_{550} \sim 0.3$, the cultures were mixed in equal volumes, induced with $250 \mathrm{ng}$ CSP ml $\mathrm{m}^{-1}$, and transferred to a water bath at $30{ }^{\circ} \mathrm{C}$. Shifting the temperature from $37{ }^{\circ} \mathrm{C}$ to $30{ }^{\circ} \mathrm{C}$ has previously been shown to increase the efficiency of competenceinduced lysis (Steinmoen et al., 2003). Uninduced mixed cultures, receiving no peptide pheromone, were run in parallel as negative controls. After $30 \mathrm{~min}$, samples were removed from the water bath and placed on ice. To measure the amount of $\beta$-galactosidase released from lysed target cells, cultures were filtered $(0.2 \mu \mathrm{m})$ to obtain cellfree supernatants. $\beta$-Galactosidase assays of supernatants were carried out in Eppendorf tubes at $30{ }^{\circ} \mathrm{C}$ and contained $240 \mu \mathrm{l} 5 \times \mathrm{Z}$ buffer ( $5 \mathrm{mM} \mathrm{MgCl}_{2}, 250 \mathrm{mM} \beta$-mercaptoethanol, $50 \mathrm{mM} \mathrm{KCl}, 0.3 \mathrm{M}$ 
Table 1. Bacterial strains and plasmids

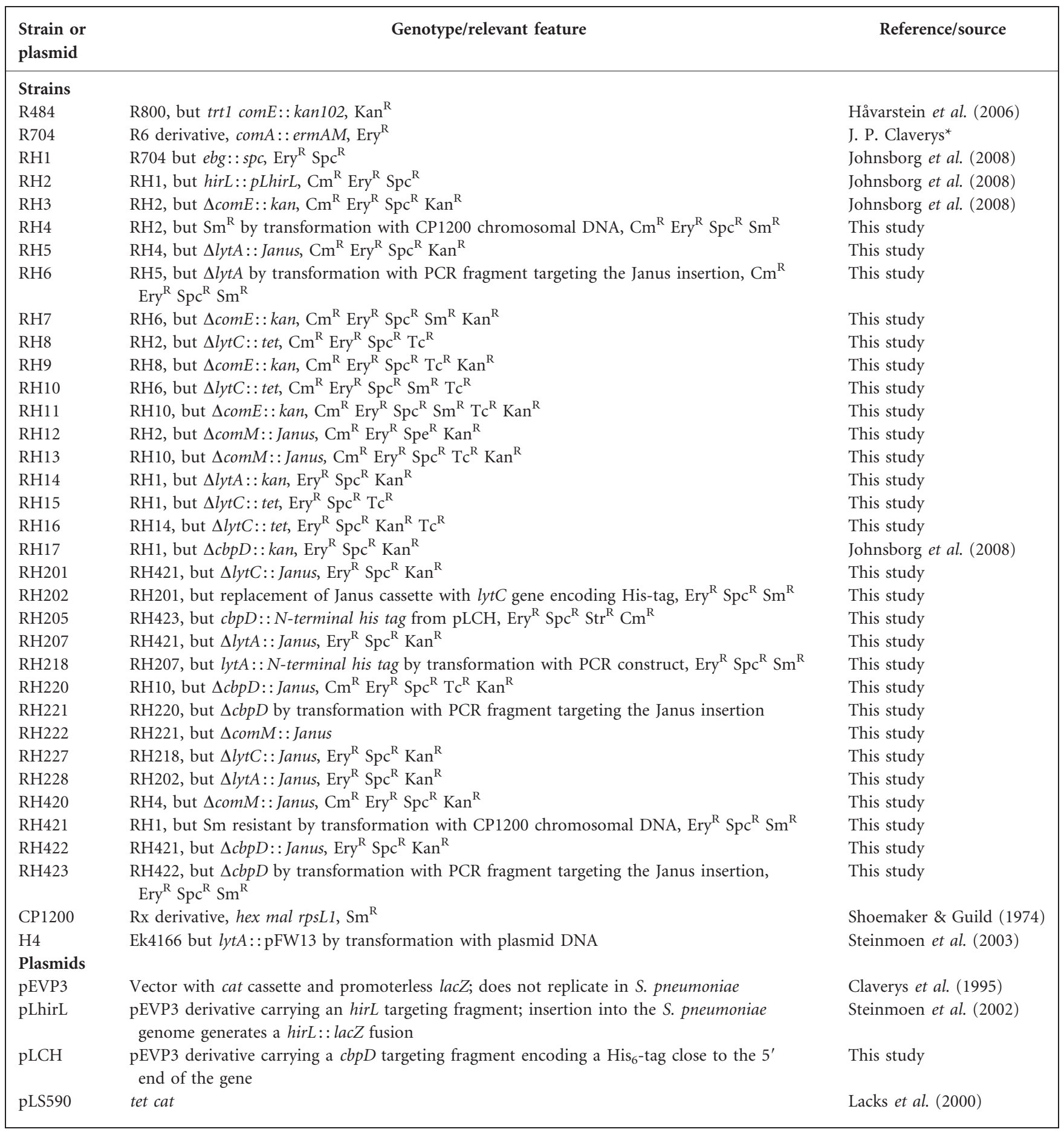

${ }^{\star}$ Gift from Professor Jean-Pierre Claverys, CNRS, LMGM-UMR, Toulouse, France.

$\mathrm{Na}_{2} \mathrm{HPO}_{4} .7 \mathrm{H}_{2} \mathrm{O}, 0.2 \mathrm{M} \mathrm{NaH}_{2} \mathrm{PO}_{4} \cdot \mathrm{H}_{2} \mathrm{O}, 4 \mathrm{mg} \mathrm{ONPG} \mathrm{ml}{ }^{-1}, \mathrm{pH} 7.0$ ), $500 \mu \mathrm{l}$ supernatant and $460 \mu \mathrm{l} \mathrm{C}$ medium. After terminating the reactions by addition of $0.5 \mathrm{ml}$ of a $1 \mathrm{M} \mathrm{Na}_{2} \mathrm{CO}_{3}$ solution, hydrolysis of ONPG was recorded in a spectrophotometer at $420 \mathrm{~nm}$. Enzyme activity was calculated according to Miller (1972).
Quantification of $\beta$-galactosidase release from monocultures of RH420, RH13 and RH222 was carried out essentially as described above. The strains were grown at $37^{\circ} \mathrm{C}$ until they reached $\mathrm{OD}_{550} 0.3$. Then, when applicable, $250 \mathrm{ng} \mathrm{CSP} \mathrm{ml}^{-1}$ and/or $1 \mathrm{mM}$ EDTA was added, and the cultures were transferred to a water bath at $30{ }^{\circ} \mathrm{C}$. 
After $30 \mathrm{~min}$, samples were collected, sterile filtered, and assayed for $\beta$-galactosidase activity.

Stability of lytic activity in supernatants. $\mathrm{RH} 1$ cultures were grown to $\mathrm{OD}_{550} \sim 0.3$ at $37{ }^{\circ} \mathrm{C}$, transferred to a $30{ }^{\circ} \mathrm{C}$ water bath and induced to competence by addition of $250 \mathrm{ng} \mathrm{CSP} \mathrm{ml}{ }^{-1}$. Twenty minutes postinduction, culture samples were sterile filtered and the resulting supernatants were immediately mixed with equal volumes of RH3 cultures $(50 \%, \mathrm{v} / \mathrm{v})$ grown to $\mathrm{OD}_{550} \sim 0.35$. After further incubation at $30{ }^{\circ} \mathrm{C}$ for $30 \mathrm{~min}, \beta$-galactosidase released from lysed RH3 target cells was quantified as described above. To measure the total $\beta$-galactosidase activity present in target cells used to test the activity of supernatants from competent RH1 cultures, the cells were completely lysed by incubation at $30{ }^{\circ} \mathrm{C}$ for $10 \mathrm{~min}$ in the presence of $0.1 \%(\mathrm{v} / \mathrm{v})$ Triton X100. After lysis, all samples were stored on ice until assayed. $\beta$ Galactosidase activity was assayed as described above except that $100 \mu \mathrm{l}$ cell lysate and $960 \mu \mathrm{l} \mathrm{C}$ medium was used in the reactions. In order to assay the stability of the lytic activity of the filtrate, it was either supplemented with $5 \mathrm{mM}$ DTT or left untreated at room temperature. Samples to be tested were withdrawn every $10 \mathrm{~min}$ for half an hour, and mixed with equal volumes of RH3 cultures at $\mathrm{OD}_{550} \sim 0.35$. To investigate whether the stimulatory effect of EDTA was due to metalloproteases released during fratricide that degraded $\mathrm{CbpD}$, sterilefiltered supernatants were prepared as described above and supplemented with $5 \mathrm{mM}$ DTT. The supernatant was then split in two, and $1 \mathrm{mM}$ EDTA was added to one of the parallels. After $1 \mathrm{~h}$ at room temperature, the supernatant without EDTA was divided again into two equal parts, one of which received $1 \mathrm{mM}$ EDTA. Immediately afterwards, supernatants were added to RH3 target cultures (50\%, v/v) and incubated at $30{ }^{\circ} \mathrm{C}$ for $30 \mathrm{~min}$. $\beta$-Galactosidase release from the target cells was quantified as described above.

Western blotting. Concentrated culture supernatants from competent pneumococci expressing His-LytA, His-LytC or His-CbpD were prepared as follows. At $\mathrm{OD}_{550} 0.3$, cultures expressing each of the Histagged lysins were divided into two parallel aliquots. One parallel received CSP $\left(250 \mathrm{ng} \mathrm{ml}^{-1}\right)$ plus $1 \%$ choline chloride, whereas the other received only CSP. After $30 \mathrm{~min}$ the cultures were sterile filtered and concentrated 70-fold using Amicon Ultra-15 centrifugal filter devices with a $10 \mathrm{kDa}$ molecular mass cutoff. The concentrated supernatants were mixed with Laemmli sample buffer and stored frozen at $-80{ }^{\circ} \mathrm{C}$ until analysed. Unconcentrated culture supernatants from competent and non-competent $\mathrm{RH} 202$ cells were prepared in the same manner, except for the step involving the Amicon Ultra-15 centrifugal filter devices.

To prepare whole-cell extracts, cultures were grown to $\mathrm{OD}_{550} 0.3$ and induced as above. Uninduced cultures were run in parallel. Thirty minutes after addition of CSP, $1 \mathrm{ml}$ samples of induced and uninduced cultures were transferred into Eppendorf tubes and centrifuged at $14500 \mathrm{~g}$ for $1 \mathrm{~min}$. The resulting pellets were dissolved in $40 \mu \mathrm{l}$ sample buffer and stored as described above. After heating to $\sim 95{ }^{\circ} \mathrm{C}$ for $5 \mathrm{~min}$, samples $(35 \mu \mathrm{l})$ were loaded onto $12.5 \%$ SDSPAGE precast gels (Bio-Rad), electrophoresed, and transferred to PVDF membranes. His-tagged LytA, LytC and CbpD proteins on the membranes were detected using the Pierce SuperSignal West Pico HisProbe kit according to the manufacturer's instructions.

Immunofluorescence microscopy. Cultures growing at $37{ }^{\circ} \mathrm{C}$ were transferred to $30{ }^{\circ} \mathrm{C}$ and induced to competence at $\mathrm{OD}_{550}$ 0.3. After $20 \mathrm{~min}$, the cells were sedimented and stained with the LIVE/DEAD BacLight bacterial viability kit (Invitrogen) according to the protocol. The cells were visualized using a Leica TCS SP5 AOBS confocal microscope.

Measurement of autolysis in RH1 and RH14 cultures subjected to varying concentrations of deoxycholate. Samples $(3 \mathrm{ml})$ of vigorously growing cultures of pneumococcal strains RH1 and RH14 $(\Delta l y t A)$ were pipetted into glass cuvettes and immediately transferred to a DU 800 spectrophotometer (Beckman Coulter) equipped with a temperature-controlled, six-cell block, cuvette holder preheated to $37{ }^{\circ} \mathrm{C}$. The spectrophotometer was preprogrammed to measure $\mathrm{OD}_{550}$ automatically every $2 \mathrm{~min}$ for $52 \mathrm{~min}$. After growing the RH1 and RH14 strains in the spectrophotometer for about $13 \mathrm{~min}$, deoxycholate was added to a final concentration of $0.1,0.05$ and $0.025 \%(\mathrm{w} / \mathrm{v})$.

\section{RESULTS}

\section{The relative contributions of LytA, LytC and CbpD to fratricide in liquid culture}

It has been reported previously that LytA and LytC can be provided by either the competent attacker or the noncompetent target cells during pneumococcal fratricide (Guiral et al., 2005). This is an interesting observation that might help elucidate the molecular mechanism behind the process. We therefore decided to extend the study of Guiral et al. (2005) by performing a more comprehensive and quantitative analysis of the contributions of LytA and LytC to competence-induced cell lysis. By using noncompetent target cells that produce cytoplasmic $\beta$ galactosidase constitutively, the level of cell lysis was determined by measuring the amount of $\beta$-galactosidase released into the growth medium during co-cultivation with competent attacker cells. Our results show that only about $0.4 \%$ of the target cells are lysed when the lyt $A$ and lyt $C$ genes have been deleted in both attacker and target cells, demonstrating that $\mathrm{CbpD}$ is not very effective on its own under the conditions used (Table 2). Nevertheless, $\mathrm{CbpD}$ is an essential component of the lysis mechanism, as attacker cells lacking this protein are totally unable to kill and lyse their non-competent siblings (Kausmally et al., 2005; Table 2). When CbpD is present, LytA and LytC both play an important role in the lysis process. LytC contributes more than LytA, however, as twice the number of target cells are lysed during co-cultivation of the strains RH14 $(\Delta l y t A)$ and RH7 $(\Delta l y t A)$ than in a corresponding experiment with the strains RH15 $(\Delta l y t C)$ and RH9 $(\Delta l y t C)$ (Table 2). In agreement with previously published results, our data show that LytA and LytC can be supplied by either attacker or target cells. However, by using a more quantitative assay than Guiral et al. (2005) we were able to compare the level of lysis obtained with cis-acting versus trans-acting LytA and LytC. Our results show that the origin of these cell wall hydrolases influences the efficiency of the fratricidal process. Almost four times as many target cells were lysed when LytA and LytC were supplied in cis (see co-cultivation of RH16 and RH3, Table 2) compared to the situation where these enzymes were supplied in trans (see co-cultivation of RH1 and RH11, Table 2). However, regardless of whether LytA and LytC are supplied in cis or in trans, they must somehow be activated by CbpD in order to attack and lyse non-competent target cells. 
Table 2. Fraction of target cells lysed during co-cultivation of various $l y t A$, lytC and $c b p D$ mutants of competent (attacker) and noncompetent (target) cells

\begin{tabular}{|lcccc|}
\hline & RH3 $(\mathbf{W T})^{*}$ & RH7 $(\boldsymbol{\Delta l y t A})$ & RH9 $(\boldsymbol{\Delta l y t C})$ & RH11 $(\boldsymbol{\Delta l y t A} \boldsymbol{\Delta l y t C})$ \\
\hline RH1 $(\mathrm{WT})^{*}$ & $33 \pm 1.4 \% \dagger$ & $20.4 \pm 0.6 \%$ & $13.5 \pm 0.7 \%$ & $5.6 \pm 0.1 \%$ \\
RH14 $(\Delta l y t A)$ & $27.2 \pm 1.5 \%$ & $19.7 \pm 1.1 \%$ & $12.0 \pm 0.9 \%$ & $1.3 \pm 0.6 \%$ \\
RH15 $(\Delta l y t C)$ & $26.2 \pm 0.5 \%$ & $10.1 \pm 1.8 \%$ & $9.2 \pm 0.3 \%$ & $0.6 \pm 0.2 \%$ \\
RH16 $(\Delta l y t A \Delta l y t C)$ & $21.0 \pm 2.0 \%$ & $4.7 \pm 1.2 \%$ & $3.2 \pm 0.5 \%$ & $0.4 \pm 0.1 \%$ \\
RH17 $(\Delta c b p D)$ & $0.03 \pm 0.02 \%$ & ND & ND & ND \\
\hline
\end{tabular}

${ }^{\star}$ The RH1 and RH3 strains are designated wild-type (WT) because they have intact $c b p D$, lytA and lytC genes.

$\dagger$ The $\beta$-galactosidase release obtained with competent wild-type attackers (RH1) co-cultivated with non-competent wild-type target cells (RH3) was 171 Miller units (mean \pm SEM). We found that this corresponds to $33 \%$ of the total $\beta$-galactosidase content of intact plus lysed RH3 target cells. Thus, on average, $33 \%$ of the target cells were lysed in this co-cultivation experiment. In all other cases, in which the experiments were carried out exactly as for RH1 and RH3, $\beta$-galactosidase release to the growth medium was measured in Miller units and then converted to percentage lysis of target cells, by dividing by 171 and multiplying by 33. ND, Not determined.

\section{Internal and external levels of CbpD, LytA, and LytC in cultures of competent and non-competent pneumococcal cells}

CbpD, LytA and LytC all contain choline-binding domains, whose function is to attach these proteins to cell wall teichoic acid (TA) and lipoteichoic acid (LTA) (López \& García, 2004). It has not been clear, however, whether CbpD and LytC, which are secreted via the Sec pathway, primarily attach to TA and LTA of the cells producing them or if they diffuse into the medium. In the case of LytA, which lacks a signal peptide, its mode of release from the cytoplasm is still a subject of dispute (López \& García, 2004). Our results show that when target cells lack both LytA and LytC, their absence can to a certain extent be compensated for by LytA and LytC originating from competent attacker cells (Table 2). Consequently, these enzymes must reach the target cells either by diffusing through the medium or via cell-cell contact. The same type of reasoning applies also for $\mathrm{CbpD}$, which is produced by competent attacker cells but act at the surface of target cells. To gain further insight into these matters we added histidine tags ( $\mathrm{His}_{6}$-tags) to the N-termini of CbpD, LytA, and LytC for detection and tracking purposes. As CbpD and LytC both contain N-terminal signal peptides, the Histag was introduced immediately downstream of the predicted signal peptidase cleavage site. The wild-type genes were replaced with the corresponding mutant genes by double-crossover recombination using the counterselectable Janus cassette as described by Sung et al. (2001). The activities of the CbpD-His, LytA-His and LytC-His proteins were found to be the same or somewhat reduced compared to their non-modified counterparts. The kinetics of LytA-dependent stationary-phase autolysis was essentially identical for the mutant strain carrying the LytA-His construct (RH218) and the wild-type strain used as control. The strain carrying the $\mathrm{CbpD}-\mathrm{His}$ construct (RH205) was, however, only about $40 \%$ as efficient as the wild-type strain in provoking lysis of strain $\mathrm{RH} 3$ when used as an attacker in co-cultivation experiments with this target strain. Co-cultivation experiments, comparing the properties of the LytC-His-carrying strain $\mathrm{RH} 228(\Delta$ comA $\Delta l y t A)$ with its wild-type equivalent RH14 ( $\Delta$ comA $\Delta l y t A)$, revealed that RH228 was about $70 \%$ as efficient as RH14 in provoking lysis of the RH11 ( $\Delta$ comE $\Delta$ lyt $\Delta \Delta$ lytC) target strain. Together, these data demonstrate that although the activities of LytC-His and CbpD-His are moderately reduced compared to the wild-type versions of these proteins, the three His-tagged lysins have retained their functionality.

Cultures of strains $\mathrm{RH} 202$, RH205, and $\mathrm{RH} 218$, producing LytC-His, CbpD-His and LytA-His, respectively, were grown at $37{ }^{\circ} \mathrm{C}$ until they reached $\mathrm{OD}_{550}$ 0.3. They were then induced to competence by addition of CSP (250 ng $\mathrm{ml}^{-1}$ ), and transferred to a water bath at $30{ }^{\circ} \mathrm{C}$. After $30 \mathrm{~min}$ at $30{ }^{\circ} \mathrm{C}$, samples of pelleted cells and sterilefiltered supernatants were harvested for Western analysis. Two experiments were run in parallel for each of the mutant strains. In one of the parallels, $1 \%$ choline chloride was added to the culture in order to prevent binding of the secreted His-tagged lysin to TA and LTA in the pneumococcal cell wall. Western blots of SDS-PAGE gels loaded with equal amounts of pelleted bacterial cells revealed that LytC is produced in similar amounts in competent and non-competent pneumococci. In contrast, CbpD was only detected in competent cells (Fig. 1a). As expected, we found that the production of LytA increases during competence. A very weak band corresponding to LytA was detected in the lane loaded with non-competent RH218 cells (not visible in Fig. 1a), whereas a considerably stronger band appeared in the lane loaded with equal amounts of competent RH218 cells. These results are in accordance with previously published data based on Northern analysis, microarray analysis and the use of reporter assays (Mortier-Barrière et al., 1998; Dagkessamanskaia et al., 2004; Peterson et al., 2004; Kausmally et al., 2005). In the present study our primary interest was to trace the lysins after they had been translocated across the cytoplasmic membrane. Cell-free 
(a)

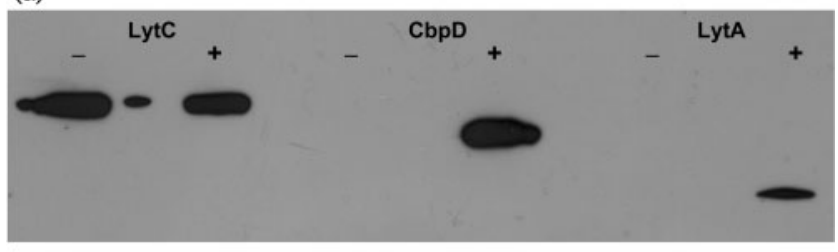

(b)

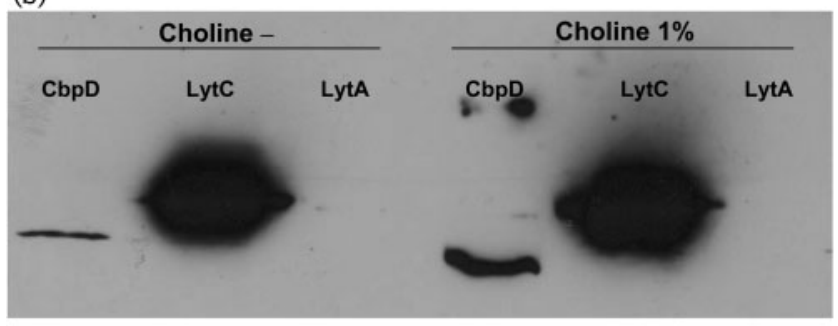

(c)

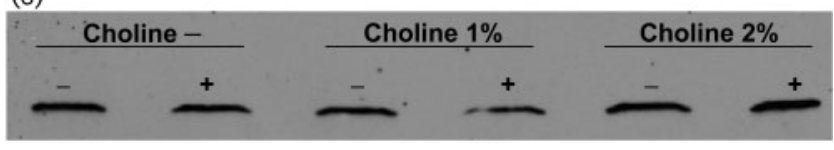

Fig. 1. Detection of His-tagged CbpD, LytA and LytC by Western analysis. (a) Equal amounts of competent $(+)$ and non-competent $(-)$ cells of the $\mathrm{RH} 202, \mathrm{RH} 205$ and $\mathrm{RH} 218$ strains were harvested and analysed by Western blotting to compare the amounts of CbpD, LytA and LytC present in whole-cell extracts. (b) Analysis of sterile-filtered supernatants from competence-induced cultures of the $\mathrm{RH} 202, \mathrm{RH} 205$ and $\mathrm{RH} 218$ strains. When the cultures reached $\mathrm{OD}_{550} 0.3,1 \%(\mathrm{w} / \mathrm{v})$ choline chloride and $250 \mathrm{ng}$ CSP $\mathrm{ml}^{-1}$ was added to one set of parallels, whereas the other (choline -) received only CSP. Thirty minutes after addition of CSP, the supernatants were collected, concentrated approximately 70-fold using Amicon Ultra-15 centrifugal filter units, and analysed by Western blotting. (c) Detection of LytC in unconcentrated culture supernatants from competent (+) and non-competent (-) $\mathrm{RH} 202$ cultures in the absence (choline - ) or presence of $1 \%$ and $2 \%$ choline.

supernatants, with or without choline chloride added, were concentrated 70-fold using Amicon Ultra-15 centrifugal filter devices (molecular mass cutoff $10 \mathrm{kDa}$ ), and analysed by SDS-PAGE followed by Western blotting. We were unable to detect LytA-His in the concentrated supernatants, demonstrating that this autolysin remains within the cytoplasm of the producer cell, or that the amount of LytA-His released to the environment is below the sensitivity level of our assay (Fig. 1b). LytC-His was found to be present in the supernatant of competent as well as non-competent cells in similar amounts, and could also readily be detected directly in unconcentrated supernatants (Fig. 1c). Unexpectedly, concentrated supernatants from RH202 cultures supplemented with 1 or $2 \%$ choline chloride did not contain more LytC-His than corresponding supernatants without choline chloride (Fig. 1c). In contrast, when strain $\mathrm{RH} 205$ was induced to competence in the presence of $1 \%$ choline chloride, the amount of CbpD-
His detected in the supernatant was much higher than in corresponding cultures where choline chloride had been omitted (Fig. 1b). This result implies that most of the secreted CbpD protein stays attached to TA and LTA in the pneumococcal cell wall, whereas only a subfraction is released to the growth medium.

\section{Activation of LytA-dependent autolysis by deoxycholate requires a lethal concentration of this detergent}

Our results show that $\mathrm{CbpD}$ somehow activates LytA during fratricide. Since a number of seemingly unrelated treatments of pneumococcal cells, such as exposure to $\mathrm{CbpD}$, detergents, freezing and thawing, hydrogen peroxide, penicillin and other cell wall inhibitors (Dubos, 1937; Tomasz \& Waks, 1975a; Mascher et al., 2006; RegevYochay et al., 2007), lead to LytA-dependent autolysis, we speculated that cell death is the common denominator that triggers the activity of LytA. To test this hypothesis we added various amounts of deoxycholate to pneumococcal strains RH1 and RH14 ( $\Delta l y t A)$ while they were in the early exponential phase of growth, and measured the effect of this treatment with respect to autolysis and cell viability. We found that at concentrations of deoxycholate of $0.1 \%$ (w/v) and above, RH1 cells lysed completely while the mutant cells (RH14) lacking the lytA gene stopped growing (Fig. 2a). When a culture of the RH1 strain was treated with $0.05 \%(\mathrm{w} / \mathrm{v})$ deoxycholate its $\mathrm{OD}_{550}$ dropped rapidly from 0.15 to about 0.08 and then continued to decline at a slow rate (Fig. 2a). Even though $0.05 \%$ (w/v) deoxycholate was not sufficient to trigger immediate autolysis of all the cells in an RH1 culture, RH14 cells subjected to the same concentration of the detergent stopped growing. Live/dead staining performed on the RH1 and RH14 cultures treated with $0.05(w / v)$ deoxycholate (Fig. 2a) revealed that all cells in these cultures were dead (Fig. 2b). Interestingly, in RH1 cultures subjected to $0.025 \%(\mathrm{w} / \mathrm{v})$ deoxycholate only a minor fraction of the cells underwent autolysis, while the surviving majority continued to grow. The LytA-deficient RH14 cells also tolerated this concentration and kept multiplying (Fig. 2a). In this case, live/dead staining of RH1 and RH14 cells showed that nearly all cells in these cultures were alive (Fig. 2b). It can be concluded from these results that there is a close correlation between cell death and activation of LytA-dependent autolysis in $S$. pneumoniae.

\section{Lytic activity in cell-free supernatants harvested from cultures of competent pneumococci}

To find out if CbpD released into the growth medium by competent pneumococci is active, sterile filtered supernatants collected from competent RH1 cultures were assayed for lytic activity against RH3 target cells. The results showed that the level of cell lysis obtained with supernatant from RH1 cultures reached approximately $50 \%$ of that obtained in standard co-cultivation experi- 
(a)

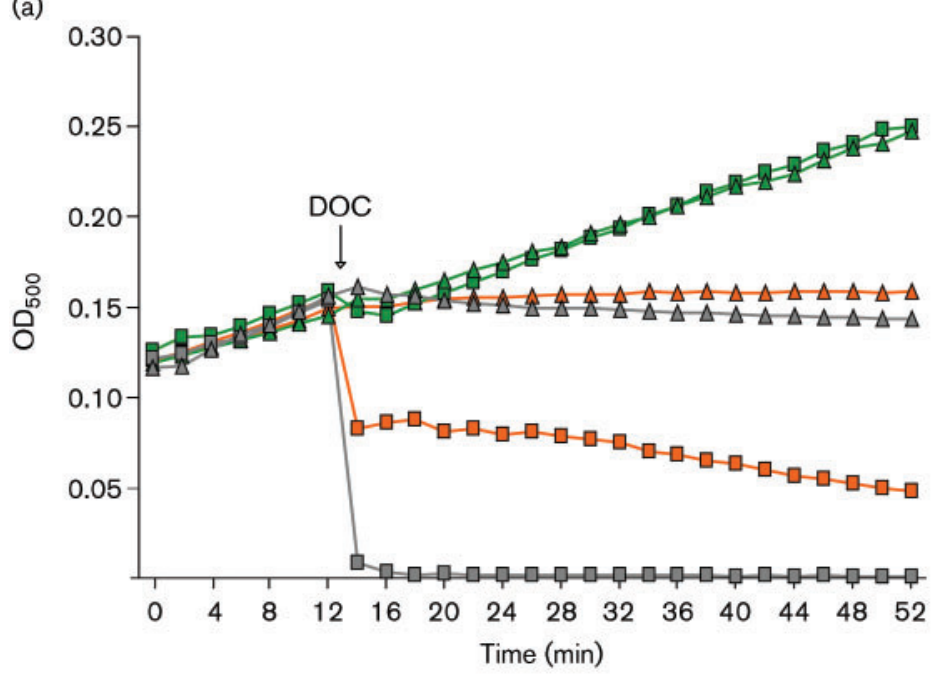

(b)
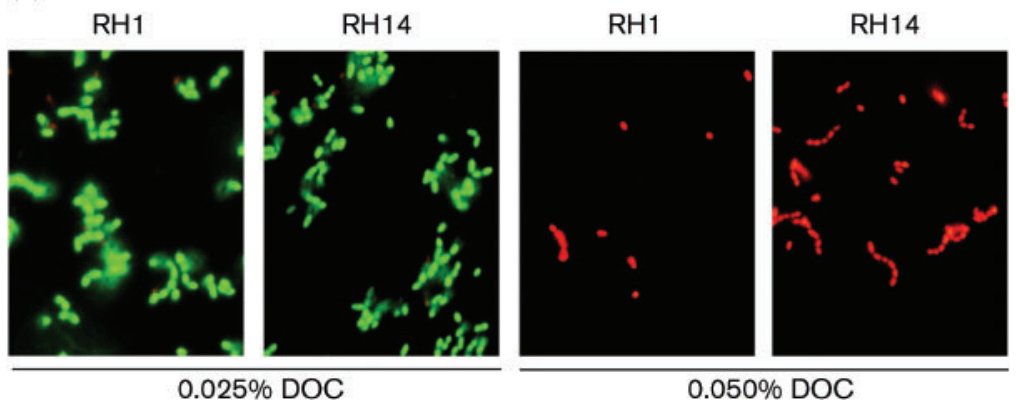

$0.050 \%$ DOC
Fig. 2. Determination of the concentration of deoxycholate (DOC) required to trigger autolysis in $\mathrm{RH} 1$ cells and death of $\mathrm{RH} 14(\Delta / y t A)$ cells. RH14 cells will not undergo autolysis when treated with DOC, as they lack the autolysin LytA. (a) Cultures of RH1 (squares) and $\mathrm{RH} 14$ cells (triangles) were grown in a spectrophotometer equipped with a Peltier temperature-controlled cuvette holder heated to $37{ }^{\circ} \mathrm{C}$. At the time indicated by the arrow, cultures were subjected to a final concentration of DOC corresponding to $0.1 \%$ (grey symbols), $0.05 \%$ (orange symbols) or $0.025 \%(w / v)$ (green symbols). Growth and autolysis were monitored by measuring the $\mathrm{OD}_{550}$. (b) $\mathrm{RH} 1$ and $\mathrm{RH} 14$ cultures treated with 0.05 and $0.025 \%(w / v)$ deoxycholate were stained with the BacLight Bacterial Viability kit (Invitrogen) according to the producer's recommendations. Live cells fluoresce green, whereas dead cells fluoresce red. The data presented are representative of the results from three independent experiments. ments between competent RH1 and non-competent RH3 cells. The lytic activity of the supernatants was completely lost upon addition of $1 \mathrm{mM}$ iodoacetamide, a general inhibitor of cysteine proteases. As the CHAP domain of CbpD shows strong homology to known cysteine proteases, this finding suggests that the lytic activity detected in sterile-filtered supernatants depends on the presence of CbpD. In accordance with this, supernatants harvested from competent cultures of the RH17 $(\Delta c b p D)$ strain displayed no lytic activity at all.

When stored at room temperature, supernatants collected from competent RH1 cultures gradually lost their ability to lyse RH3 target cells (Fig. 3). The lytic activity dropped by two-thirds in $30 \mathrm{~min}$, suggesting that $\mathrm{CbpD}$ is somehow inactivated and/or degraded by proteases. Interestingly, addition of $5 \mathrm{mM}$ DTT to the RH1 supernatants slowed the decay rate considerably (Fig. 3). In an attempt to elucidate the mechanism behind this stabilizing effect we added $5 \mathrm{mM}$ DTT to supernatants collected from competence-induced RH17 $(\Delta c b p D)$ cultures, i.e. supernatants lacking $\mathrm{CbpD}$. When these supernatants were mixed with RH3 target cultures $(50 \%, \mathrm{v} / \mathrm{v})$ no $\beta$-galactosidase release was detected (result not shown). We therefore concluded that DTT acts directly on $\mathrm{CbpD}$, and that the reducing agent probably stabilizes the activity of $\mathrm{CbpD}$ by protecting its active-site cysteine from oxidation.

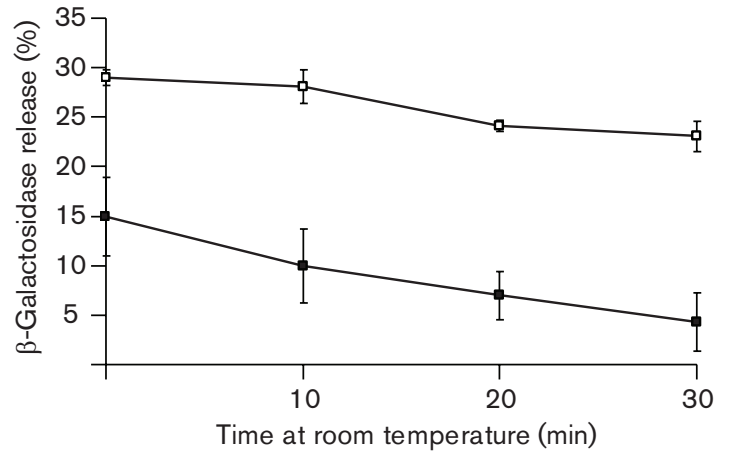

Fig. 3. Decay rate of the lytic activity present in the growth medium of competent pneumococcal cultures in the presence ( $\square$ ) and absence ( $\boldsymbol{\square}$ ) of DTT. Sterile-filtered $\mathrm{RH} 1$ supernatants were left at room temperature for various periods of time and mixed $(50 \%, v / v)$ with non-competent $\mathrm{RH} 3$ target cells $\left(\mathrm{OD}_{550} 0.35\right)$ producing intracellular $\beta$-galactosidase. Release of $\beta$-galactosidase from the target cells (as indicated on the $y$-axis) represents the percentage of $\beta$-galactosidase activity measured in the growth medium relative to the total amount of this enzyme present in the $\mathrm{RH} 3$ cultures (extracellular + intracellular $\beta$-galactosidase). Results presented are the means \pm SEM of three independent experiments. 
To determine whether proteolytic degradation also contributed to the declining CbpD activity observed in Fig. 3, various protease inhibitors were employed. We found that addition of $1 \mathrm{mM}$ EDTA strongly increased the lytic activity of supernatants harvested from competent RH1 cells. When supernatants collected from these cells were supplemented with $5 \mathrm{mM}$ DTT, placed at room temperature for $1 \mathrm{~h}$, and subsequently mixed with cultures of RH3 target cells $(50 \% \mathrm{v} / \mathrm{v})$ for $30 \mathrm{~min}$, approximately $20 \%$ of the target cells were lysed. If, however, supernatants from competent RH1 cells were supplemented with $1 \mathrm{mM}$ EDTA in addition to $5 \mathrm{mM}$ DTT, the fraction of target cells lysed increased to around $69 \%$. This finding suggested that a $\mathrm{CbpD}$-degrading metalloprotease, whose activity is inhibited by EDTA, is present in the supernatants. To establish whether this could be the case we performed experiments in which EDTA was added to RH1 supernatants after they had been rested at room temperature for $1 \mathrm{~h}$, i.e. immediately before they were mixed with cultures of RH3 target cells. Following this procedure, $65 \%$ of the target cells were lysed. The fact that EDTA has the same stimulatory effect, regardless of whether it is added to RH1 supernatants before or after they were incubated at room temperature for $1 \mathrm{~h}$, argues strongly against the idea that EDTA protects $\mathrm{CbpD}$ from proteolytic degradation. Further control experiments showed that the chelating agent alone was not responsible for the stimulatory effect, as no lysis took place when supernatants from competent RH17 $(\Delta c b p D)$ cultures supplemented with 1 mM EDTA were mixed with RH3 target cells. Neither did the presence of EDTA affect the content of cytoplasmic $\beta$-galactosidase in RH3 cells treated with this compound for $30 \mathrm{~min}$. Although EDTA does not appear to protect against proteolytic degradation, our results clearly show that its stimulatory effect depends on the presence of $\mathrm{CbpD}$. In other words, removal of divalent cations by chelation somehow enhances the efficiency of the fratricide process when it takes place in liquid $\mathrm{C}$ medium under the conditions employed in this study.

\section{The activity of CbpD increases dramatically in the presence of EDTA}

To further elucidate the effect of EDTA, a series of experiments were carried out with strains in which the immunity gene comM had been deleted. When a monoculture of strain RH420 ( $\Delta$ comM hirL::lacZ) is induced to competence at $\mathrm{OD}_{550} 0.3$, approximately $20 \%$ of the cells are lysed. In contrast, very little lysis (1-2\%) is observed in an RH2 (hirL:: lacZ) culture, which expresses the ComM immunity protein during competence. The reason why a monoculture lacking the ComM immunity protein is not completely lysed is not understood. As shown in Fig. 4(a), the level of competence-induced cell lysis increased almost threefold in RH420 ( $\Delta$ comM hirL:: lacZ) cultures treated with $1 \mathrm{mM}$ EDTA compared to untreated cultures. On the other hand, competenceinduced cultures of strain RH222, lacking ComM, CbpD,
LytA and LytC, did not lyse at all. Intriguingly, competent cultures of RH13 lysed efficiently in the presence of $1 \mathrm{mM}$ EDTA, but very poorly without this metal chelator (Fig. 4a). The only difference between RH222 and RH13 is that the latter strain harbours a functional $c b p D$ gene. Live/dead staining of competent and non-competent cultures of the RH421, RH222 and RH13 strains confirmed that in the presence of EDTA, the ability of CbpD to kill target cells on its own increases dramatically (Fig. 4b).

\section{DISCUSSION}

Our results show that when competent pneumococci were co-cultivated with their non-competent siblings, efficient lysis of the non-competent target cells depended on $\mathrm{CbpD}$ and the autolysins LytA and/or LytC. CbpD produced by the competent attacker cells was absolutely required, but was not very active on its own under the conditions employed. In the presence of LytA and/or LytC, however, a significant fraction of the target cells was lysed. An important step towards understanding the mechanism behind the lethal activity of CbpD will be to identify the cleavage site of its CHAP domain. Most characterized CHAP domains are cysteine proteases that function as peptidoglycan hydrolases. It is therefore reasonable to assume that the CHAP domain of $\mathrm{CbpD}$ cleaves within the peptidoglycan stem peptides or the seryl-alanine/alanylalanine dipetide bridges linking these stem peptides. Removal of the dipeptide bridges in a pneumococcal $\Delta$ comE strain by insertion of a Janus cassette in the murM gene did not affect the strain's susceptibility to CbpD (Fiser et al., 2003; data not shown). This strongly indicates that the CHAP domain of $\mathrm{CbpD}$, which has been demonstrated to be essential for its function (Håvarstein et al., 2006), cleaves within the murein stem-peptide rather than in the dipeptide bridges.

The data presented in Table 2 show that LytC as well as LytA contributes significantly to fratricide. Both autolysins can be provided in trans by the attacker cells, but lysis of target cells is considerably more efficient when they are provided in cis. As depicted in Fig. 1, LytC is released to the growth medium in relatively high amounts by cells possessing a functional lytC gene. This result readily explains how the protein becomes available to LytCdeficient target cells during co-cultivation with LytCproficient attackers. We do not know, however, whether the pool of LytC detected in the growth medium mainly represents free enzyme or enzyme attached to TA in shed cell wall material. In contrast to the abundance of extracellular LytC present in pneumococcal cultures, extracellular LytA is either absent or present in only very minute amounts. Even in the presence of $1 \%$ choline, which should elute any LytA attached to TA and LTA in the pneumococcal cell wall, no band corresponding to LytA could be identified on the Western blots. This negative result is in accordance with data published by Yother \& White (1994), who concluded that LytA is probably an 


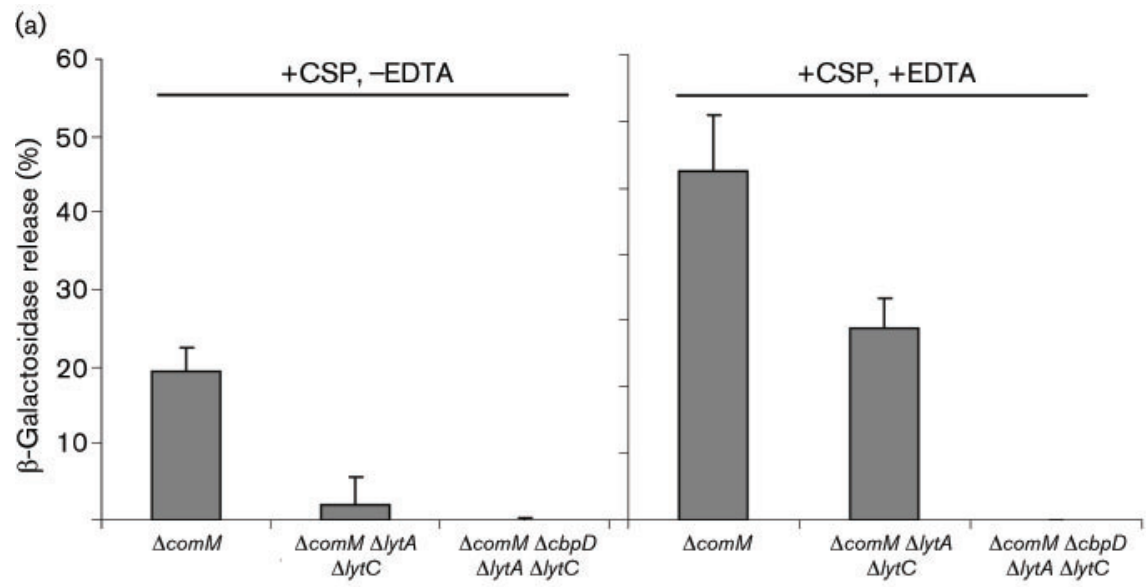

(b)
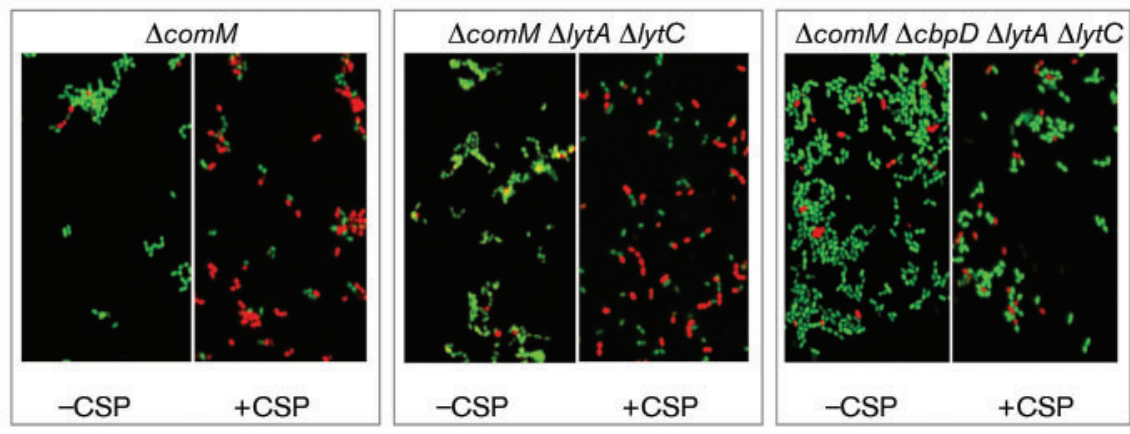

Fig. 4. Effect of EDTA on the efficiency of competence-induced self-lysis. All mutant strains used were deficient in ComM, an immunity protein that protects competent cells from succumbing to the activity of their own lysins. When monocultures of comM mutants are induced to competence a fraction of the cells will lyse. (a) $\beta$-Galactosidase release from CSP-induced cultures of $\mathrm{RH} 420(\Delta c o m M), \mathrm{RH} 13(\Delta / y t A \Delta / y t \mathrm{C} \Delta c o m M)$ and $\mathrm{RH} 222(\Delta c b p D \Delta / y t A \Delta / y t C \Delta c o m M)$. The cultures were either untreated (left panel) or supplemented with $1 \mathrm{mM}$ EDTA (right panel) at the time of competence induction (the addition of CSP). After 30 min incubation at $30{ }^{\circ} \mathrm{C}$ the percentage $\beta$-galactosidase release, i.e. extracellular relative to total $\beta$-galactosidase activity, was determined using the same procedure as explained in the footnote to Table 2 . Results presented are the means \pm SEM of three independent experiments. (b) Live/dead staining of EDTA-treated (1 mM) non-competent (left panel) and competent (right panel) cultures of each of the mutant strains $\mathrm{RH} 420(\Delta c o m M), \mathrm{RH} 13(\Delta / y t A, \Delta / y t C, \Delta c o m M)$ and $\mathrm{RH} 222(\Delta c b p D, \Delta / y t A, \Delta / y t C$, $\Delta$ comM). The cultures were harvested 20 min after CSP induction and stained with the BacLight Bacterial Viability kit (Invitrogen) according to the producer's recommendations. Live cells fluoresce green, whereas dead cells fluoresce red.

intracellular protein. As we applied a very sensitive detection system for His-tagged proteins, and concentrated our supernatant samples 70 -fold, our assay must be considered significantly more sensitive than the one employed by Yother \& White (1994). Taking this into account, it is highly likely that LytA is stored intracellularly, presumably associated with the inside of the cytoplasmic membrane, and that it is released only when the integrity of this membrane is lost. The results of an earlier study by Briese \& Hakenbeck (1985), examining the distribution of LytA in different cellular fractions, lend support to this view. Our finding that a lethal concentration of deoxycholate is required to trigger LytA-dependent autolysis points in the same direction. Upon adding $0.05 \%(\mathrm{w} / \mathrm{v})$ deoxycholate to an RH1 culture we observed that all the cells died, whereas only about half of the cells underwent autolysis. This result indicates that pneumococcal cells are killed at a slightly lower concentration of deoxycholate than is required to initiate LytA-dependent autolysis, suggesting that release of LytA from an intracellular membrane-associated depot and not cell death per se triggers the autolytic mechanism. However, previous studies have shown that addition of extracellular purified LytA to exponentially growing LytA-deficient pneumococci does not trigger autolysis before the cells have reached the stationary phase (Díaz et al., 1990). Similarly, Tomasz \& Waks (1975) demonstrated that extracellular LytA is active when added to cell wall material or mechanically disrupted unfractionated bacteria, but is immediately inhibited when adsorbed to living cells. Evidently some mechanism exists that protects metabolically active pneumococci against their own autolysin. Based on previously published reports, 
some of which have been referred to above, and the results presented in the current study, we propose the following mechanism of action of LytA: (i) in living cells LytA is not normally present in the cell wall, but is probably stored on the inside of the cytoplasmic membrane, (ii) various treatments that kill pneumococcal cells bring about loss of integrity of the cytoplasmic membrane, leading to release of LytA followed by autolysis, (iii) when LytA is released the enzyme must bind to phosphorylcholine residues present on TA and LTA in the pneumococcal cell wall in order to convert to its active form (Tomasz \& Westphal, 1971; Giudicelli \& Tomasz, 1984), and (iv) if the enzyme is added exogenously to living cells its activity is somehow suppressed.

Considering the differences between LytA and LytC with respect to localization, how do they contribute to fratricide and how are they activated by CbpD? Evidently, the relatively high concentration of LytC detected in the medium of non-competent pneumococcal cultures in the exponential phase of growth is not harmful to the cells, demonstrating that LytC is inactive under these circumstances. Thus, our results strongly indicate that $\mathrm{CbpD}$ activates LytC through direct interaction, through a mediator, or indirectly by, for example, introducing specific cuts in the peptidoglycan of target cells. According to this hypothesis, the combined or successive action of CbpD and LytC lyses the target cells and releases the $\beta$-galactosidase reporter enzyme. LytA-mediated lysis, on the other hand, probably represents an autolytic process triggered by $\mathrm{CbpD}$. As mentioned above, it is well documented that exogenously added LytA is not able to degrade the cell wall of metabolically active cells (Lacks, 1970; Tomasz \& Waks, 1975b; Díaz et al., 1990). Therefore, activation of LytA by $\mathrm{CbpD}$ probably requires that $\mathrm{CbpD}$ alone, or together with LytC, kills the target cells first through limited hydrolysis of their cell walls. Presumably the damage introduced by $\mathrm{CbpD}$ or $\mathrm{CbpD} / \mathrm{LytC}$ will cause disruption of the cytoplasmic membrane followed by release of intracellular LytA. As a consequence extensive LytA-mediated autolysis takes place, allowing efficient release of the $\beta$-galactosidase reporter enzyme. Although our results show that $\mathrm{CbpD}$ is able to kill and lyse a minor fraction of the target cells on its own (see Table 2), there is reason to believe that the $\beta$-galactosidase release assay employed underestimates the fraction of target cells killed directly by $\mathrm{CbpD}$. Since the $\beta$-galactosidase enzyme used as a reporter is a tetramer with a molecular mass of about 420 $\mathrm{kDa}$, the presence of relatively large pores or total disintegration of the cell wall is required for efficient release of the enzyme. For this reason, cells that are killed by $\mathrm{CbpD}$ via limited cell wall hydrolysis that leaves their peptidoglycan sacculus largely intact might escape detection. The ability of LytA to act in trans is probably due to the fact that $1-2 \%$ of the attacker cells are lysed by other attackers during co-cultivation with non-competent target cells. The reason for this is probably that a small fraction of attacker cells does not respond to CSP under the conditions used, and therefore do not develop immunity. LytA leaking from these cells will presumably contribute to increased lysis of target cells that have been killed, but not completely disrupted by $\mathrm{CbpD}$ or $\mathrm{CbpD/LytC}$.

The Western analyses presented in Fig. 1 show that 30 min after competence induction most secreted CbpD resides in the cell walls of the producer cells. This finding is somewhat counterintuitive, as it would be expected that CbpD must be excreted into the environment in order to reach the target cells. A possible explanation for this result is that fratricide under natural conditions involves cell-cell contact between attacker and target cells. As $\mathrm{CbpD}$ is probably attached to the TA and LTA protruding from the surface of competent cells, it is conceivable that direct contact between the cell walls of competent and non-competent cells could result in lysis of the latter. Undoubtedly, close contact between donor and recipient cells would greatly increase the chance that DNA released from the lysed target cells is captured and taken up by competent attackers. The fact that $\mathrm{CbpD}$-mediated gene transfer between different strains of pneumococcus, and between pneumococci and their commensal relatives, most likely takes place within biofilms in the nasopharynx, supports the idea that close contact between attacking and attacked cells is the natural situation at which fratricide takes place.

Interestingly, addition of $1 \mathrm{mM}$ EDTA strongly increases the efficacy of the fratricide mechanism, and enables CbpD to kill and lyse non-competent target cells efficiently on its own (see Fig. 4). This finding indicates that divalent cations are involved in the regulation of $\mathrm{CbpD}$ activity. Alternatively, the presence of the metal chelator may interfere with the physiology of the target cells in a way that makes them more susceptible to CbpD. However, as pneumococcal cultures treated with $1 \mathrm{mM}$ EDTA grow at the same rate as untreated cultures for up to $1 \mathrm{~h}$ after addition of the chelator (results not shown), this alternative does not seem plausible. It is therefore likely that the ability of EDTA to stimulate fratricide is due to a specific mechanism rather than a general toxic effect on the target cells. $\mathrm{CbpD}$ may, for example, contain binding site(s) for divalent cations that upon removal by EDTA cause a conformational change that enhances the activity of this putative peptidoglycan hydrolase. It is also possible that divalent cations bound to the phosphate groups of TA and LTA or other anionic sites in the cell wall interfere with binding of CbpD to its target sites in the cell wall, and that removal of these ions makes the substrate more accessible for the enzyme (Neuhaus \& Baddiley, 2003). These questions will be the subject of future investigations. Whatever the nature of the EDTA effect, our findings suggest that divalent cations play an important role in the regulation of fratricide under natural conditions.

\section{ACKNOWLEDGEMENTS}

This work was supported by the Research Council of Norway, and FUGE/CAMST. 


\section{REFERENCES}

Bateman, A. \& Rawlings, N. D. (2003). The CHAP domain: a large family of amidases including GSP amidase and peptidoglycan hydrolases. Trends Biochem Sci 28, 234-237.

Briese, T. \& Hakenbeck, R. (1985). Interaction of the pneumococcal amidase with lipoteichoic acid and choline. Eur J Biochem 146, 417427.

Chi, F., Nolte, O., Bergmann, C., Ip, M. \& Hakenbeck, R. (2007). Crossing the barrier: evolution and spread of a major class of mosaic $p b p 2 x$ in Streptococcus pneumoniae, S. mitis, and S. oralis. Int J Med Microbiol 297, 503-512.

Claverys, J. P. \& Håvarstein, L. S. (2007). Cannibalism and fratricide: mechanisms and raison d'être. Nat Rev Microbiol 5, 219-229.

Claverys, J. P., Dintilhac, A., Pestova, E. V., Martin, B. \& Morrison, D. A. (1995). Construction and evaluation of new drug-resistance cassettes for gene disruption mutagenesis in Streptococcus pneumoniae, using an ami test platform. Gene 164, 123-128.

Dagkessamanskaia, A., Moscoso, M., Hénard, V., Guiral, S., Overweg, K., Reuter, M., Martin, B., Wells, J. \& Claverys, J. P. (2004). Interconnection of competence, stress and CiaR regulons in Streptococcus pneumoniae: competence triggers stationary phase autolysis of ciaR mutant cells. Mol Microbiol 51, 1071-1086.

Díaz, E., López, R. \& García, J. L. (1990). Chimeric phage-bacterial enzymes: a clue to the modular evolution of genes. Proc Natl Acad Sci U S A 87, 8125-8129.

Dubos, R. J. (1937). Mechanism of the lysis of pneumococci by freezing and thawing, bile, and other agents. J Exp Med 66, 101-112.

Fiser, A., Sergio, R. F. \& Tomasz, A. (2003). Cell wall branches, penicillin resistance and the secrets of the MurM protein. Trends Microbiol 11, 547-553.

Giudicelli, S. \& Tomasz, A. (1984). Attachment of pneumococcal autolysin to wall teichoic acids, an essential step in enzymatic wall degradation. J Bacteriol 158, 1188-1190.

Guiral, S., Mitchell, T. J., Martin, B. \& Claverys, J. P. (2005). Competence-programmed predation of noncompetent cells in the human pathogen Streptococcus pneumoniae: genetic requirements. Proc Natl Acad Sci U S A 102, 8710-8715.

Hakenbeck, R. (1995). Target mediated resistance to $\beta$-lactam antibiotics. Biochem Pharmacol 50, 1121-1127.

Håvarstein, L. S., Coomaraswami, G. \& Morrison, D. A. (1995). An unmodified heptadecapeptide pheromone induces competence for genetic transformation in Streptococcus pneumoniae. Proc Natl Acad Sci U S A 92, 11140-11144.

Håvarstein, L. S., Gaustad, P., Nes, I. F. \& Morrison, D. A. (1996). Identification of the streptococcal competence-pheromone receptor. Mol Microbiol 21, 863-869.

Håvarstein, L. S., Martin, B., Johnsborg, O., Granadel, C. \& Claverys, J. P. (2006). New insights into the pneumococcal fratricide: relationship to clumping and identification of a novel immunity factor. Mol Microbiol 59, 1297-1307.

Hiller, N. L., Janto, B., Hogg, J. S., Boissy, R., Yu, S., Powell, E., Keefe, R., Ehrlich, N. E., Shen, K. \& other authors (2007). Comparative genomic analyses of seventeen Streptococcus pneumoniae strains: insights into the pneumococcal supragenome. J Bacteriol 189, 8186-8195.

Hui, F. M. \& Morrison, D. A. (1991). Genetic transformation in Streptococcus pneumoniae: nucleotide sequence analysis shows $\operatorname{com} A$, a gene required for competence induction, to be a member of the bacterial ATP-dependent transport protein family. J Bacteriol 173, $372-381$
Jenkins, S. G., Brown, S. D. \& Farrell, D. J. (2008). Trends in antibacterial resistance among Streptococcus pneumoniae isolated in the USA: update from PROTEKT US Years 1-4. Ann Clin Microbiol Antimicrob 7, 1-11.

Johnsborg, O., Eldholm, V. \& Håvarstein, L. S. (2007). Natural genetic transformation: prevalence, mechanisms and function. Res Microbiol 158, 767-778.

Johnsborg, O., Eldholm, V., Bjørnstad, M. L. \& Håvarstein, L. S. (2008). A predatory mechanism dramatically increases the efficiency of lateral gene transfer in Streptococcus pneumoniae and related commensal species. Mol Microbiol 69, 245-253.

Kausmally, L., Johnsborg, O., Lunde, M., Knutsen, E. \& Håvarstein, L. S. (2005). Choline-binding protein D (CbpD) in Streptococcus pneumoniae is essential for competence-induced cell lysis. J Bacteriol 187, 4338-4345.

Lacks, S. A. (1970). Mutants of Diplococcus pneumoniae that lack deoxy-ribonucleases and other activities possibly pertinent to genetic transformation. J Bacteriol 101, 373-383.

Lacks, S. A. \& Hotchkiss, R. D. (1960). A study of the genetic material determining an enzyme activity in pneumococcus. Biochim Biophys Acta 39, 508-517.

Lacks, S. A., Ayalew, S., de la Campa, A. G. \& Greenberg, B. (2000). Regulation of competence for genetic transformation in Streptococcus pneumoniae: expression of $d p n A$, a late competence gene encoding a DNA methyltransferase of the DpnII restriction system. Mol Microbiol 35, 1089-1098.

Lee, M. S. \& Morrison, D. A. (1999). Identification of a new regulator in Streptococcus pneumoniae linking quorum sensing to competence for genetic transformation. J Bacteriol 181, 5004-5016.

López, R. \& García, E. (2004). Recent trends in the molecular biology of pneumococcal capsules, lytic enzymes, and bacteriophage. FEMS Microbiol Rev 28, 553-580.

Mascher, T., Heintz, M., Zähner, D., Merai, M. \& Hakenbeck, R. (2006). The CiaRH system of Streptococcus pneumoniae prevents lysis during stress induced by treatment with cell wall inhibitors and by mutations in $p b p 2 x$ involved in $\beta$-lactam resistance. J Bacteriol 188, 1959-1968.

Miller, J. H. (1972). Experiments in Molecular Genetics. Cold Spring Harbor, NY: Cold Spring Harbor Laboratory.

Mortier-Barrière, I., de Saizieu, A., Claverys, J. P. \& Martin, B. (1998). Competence-specific induction of recA is required for full recombination proficiency during transformation in Streptococcus pneumoniae. Mol Microbiol 27, 159-170.

Neuhaus, F. C. \& Baddiley, J. (2003). A continuum of anionic charge: structures and functions of D-alanyl-teichoic acids in gram-positive bacteria. Microbiol Mol Biol Rev 67, 686-723.

Obaro, S. \& Adegbola, R. (2002). The pneumococcus: carriage, disease, and conjugate vaccines. J Med Microbiol 51, 98-104.

Pestova, E. V., Håvarstein, L. S. \& Morrison, D. A. (1996). Regulation of competence for genetic transformation in Streptococcus pneumoniae by an auto-induced peptide pheromone and a two-component regulatory system. Mol Microbiol 21, 853-862.

Peterson, S. N., Sung, C. K., Cline, R., Desai, B. V., Snesrud, E. C., Luo, P., Walling, J., Li, H., Mintz, M. \& other authors (2004). Identification of competence pheromone responsive genes in Streptococcus pneumoniae by use of DNA microarrays. Mol Microbiol 51, 1051-1070.

Regev-Yochay, G., Trzcinski, K., Thompson, C. M., Lipsitch, M. \& Malley, R. (2007). SpxB is a suicide gene of Streptococcus pneumoniae and confers a selective advantage in an in vivo competitive colonization model. J Bacteriol 189, 6532-6539. 
Rigden, D. J., Jedrzejas, M. J. \& Galperin, M. Y. (2003). Amidase domains from bacterial and phage autolysins define a family of $\gamma$-D,Lglutamate-specific amidohydrolases. Trends Biochem Sci 28, 230-234.

Shoemaker, N. B. \& Guild, W. R. (1974). Destruction of low efficiency markers is a slow process occuring at a heteroduplex stage of transformation. Mol Gen Genet 128, 283-290.

Steinmoen, H., Knutsen, E. \& Håvarstein, L. S. (2002). Induction of natural competence in Streptococcus pneumoniae triggers lysis and DNA release from a subfraction of the cell population. Proc Natl Acad Sci U S A 99, 7681-7686.

Steinmoen, H., Teigen, A. \& Håvarstein, L. S. (2003). Competence induced cells of Streptococcus pneumoniae lyse competence-deficient cells of the same strain during co-cultivation. J Bacteriol 185, 7176-7183.

Sung, C. K., Li, H., Claverys, J. P. \& Morrison, D. A. (2001). An rpsL cassette, Janus, for gene replacement through negative selection in Streptococcus pneumoniae. Appl Environ Microbiol 67, 51905196.
Tomasz, A. \& Waks, S. (1975a). Mechanism of action of penicillin: triggering of the pneumococcal autolytic enzyme by inhibitors of cell wall synthesis. Proc Natl Acad Sci U S A 72, 4162-4166.

Tomasz, A. \& Waks, S. (1975b). Enzyme replacement in a bacterium: phenotypic correction by the experimental introduction of the wild type enzyme into a live enzyme defective mutant pneumococcus. Biochem Biophys Res Commun 65, 1311-1319.

Tomasz, A. \& Westphal, M. (1971). Abnormal autolytic enzyme in a pneumococcus with altered teichoic acid composition. Proc Natl Acad Sci U S A 68, 2627-2630.

Ween, O., Gaustad, P. \& Håvarstein, L. S. (1999). Identification of DNA binding sites for ComE, a key regulator of natural competence in Streptococcus pneumoniae. Mol Microbiol 33, 817-827.

Yother, J. \& White, J. M. (1994). Novel surface attachment mechanism of the Streptococcus pneumoniae protein PspA. J Bacteriol 176, 2976-2985.

Edited by: T. Msadek 